\section{Device for eluting proteins from starch gel by freezing and thawing}

T. R. C. BOYDE ${ }^{1}$ From the Department of Clinical Biochemistry, University of Newcastle-uponTyne

If starch gel is frozen and thawed, its structure is so changed that most of the water and protein can be extracted by centrifugation (Smithies, 1955) or by

'Present address: Department of Biochemistry, Royal College of Surgeons of England, Lincolns Inn Fields, London, W.C.2

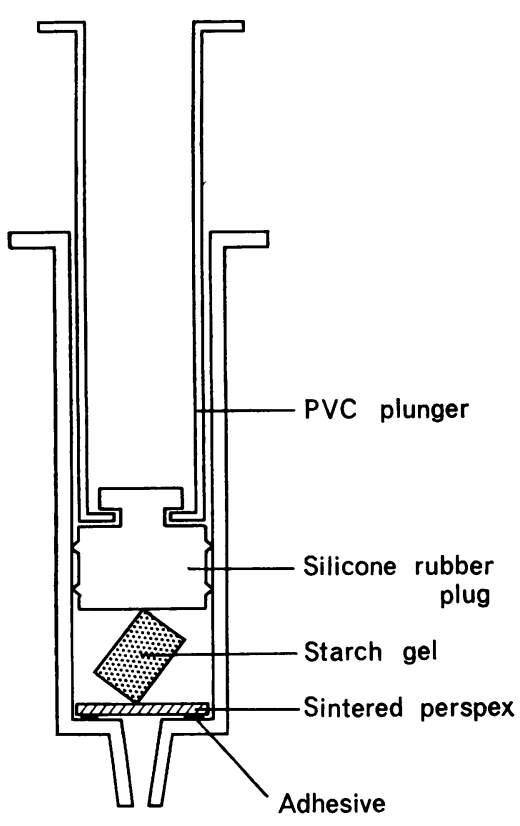

Fig. 1. The device is based upon a $10 \mathrm{ml}$ disposable syringe made of polyvinyl chloride, but having a close-fitting plug of artificial rubber attached to the end of the plunger. The minimum quantity of perspex cement $(4 \%$ perspex in chloroform) is placed round the perimeter of the end of the barrel (inside), using a Pasteur pipette. A disc of sintered perspex (Fisons Scientific Instruments Ltd, Loughborough) is cut to fit inside the barrel, and is then forced down with the plunger until it lies in contact with the adhesive. The plunger is then withdrawn, and the syringe laid aside for 24 hours to harden. Alternative adhesives might be tried with advantage.

Received for publication 27 August 1968.

\section{Letter to the Editor}

\section{A MODIFIED SCREENING TEST FOR GLYCOSAMINOGLYCAN EXCRETION}

The cetylpyridinium chloride turbidity screening test for glycosaminoglycan excretion discussed by Manley, Severn, and Hawksworth (1968) has been used in this laboratory. In this method (cetylpyridinium chloride turbidity) the precipitation time of four minutes is critical since, after this time interval, turbidity may continue to rise or may fall due to aggregation of particles. As a result of this, false positive results may be found in normal subjects. Precipitation of glycosaminoglycan by cetylpyridinium is also affected by ionic strength and $p \mathrm{H}$, false positive results also being found in urine of high $p \mathrm{H}$ or high ionic strength. Therefore, it seemed desirable to try and overcome the critical time dependence and adjust the urine $p H$ with a buffer in such a way that differences in final ionic strength and $p \mathrm{H}$ between samples would be negligible. Preliminary experiments showed that a citrate buffer at $p \mathrm{H} 4.8$ was

Device for eluting proteins from starch by freezing and thawing - continued.

squeezing. This is conveniently done in the device illustrated here. Portions of the completed gel are cut out, placed in the barrel of the syringe, and then frozen by keeping at $-20^{\circ}$ for two hours. After allowing to thaw on the bench for two hours, fluid is expressed, and the syringe and gel matrix are then washed as often as desired by drawing up water or a suitable buffer solution and re-expressing after an interval of 10 minutes to 24 hours. The recovery of haemoglobin was virtually complete after two rinses, but serum albumin proved more difficult, only some 80 to $90 \%$ being extracted after three rinses.

The advantages of this device are that it is convenient, at least for small numbers, and that it is easy to rinse the gel matrix. Only about $75 \%$ of the water contained in the gel is recovered at the first expression or centrifugation, and rinsing is essential if recoveries are to be quantitative. The chief disadvantages are shared with any procedure for extraction by freezing and thawingthe sample is contaminated with polysaccharides, and even some protein, derived from the gel itself.

Bocci (1963) described the use of metal-glass syringes fitted with filter paper discs to extract protein by the freezing and thawing process, from starch gel expanded with Pevikon C870. Filters of this kind have proved too weak to stand up to the pressures used in expressing gels made of starch alone. Also, if the gel matrix is to be rinsed by aspirating buffer, the filter must be firmly attached to the end of the syringe barrel. A demountable system of screw clamps can be used instead of simply glueing the porous disc in place, but it is more expensive.

\section{REFERENCES}

Bocci, V, (1963). Nature (Lond.), 197, 491. Smithies, O. (1955). Biochem. J., 61, 629. 


\section{Letters to the Editor}

\section{Serum antibodies in giardiasis}

We read with interest the article by Ridley and Ridley on serum antibodies in giardiasis (J. clin. Path., 1976, 29, 30-34). We offer this additional information.

Earlier workers have in fact studied and reported on the serological response to Giardia lamblia infection. Two Romanian workers (Halita and Isaicu, 1946) showed that an antibody capable of fixing complement is produced in giardiasis. And Vinnikov in the Soviet Union in 1949 reported that an intradermal test was demonstrable in this disease. Both groups of workers used as antigen Giardia trophozoites recovered from the host by duodenal intubation, and, like Ridley and Ridley, both were frustrated in the further development of their tests by the lack of a consistent supply of pure antigen.

We reported in 1974 the successful use of the indirect immunofluorescent test in demonstrating a serological response in giardiasis. As antigen we used $G$. muris and $G$. duodenalis trophozoites washed directly from small intestine. The following are our results in brief: The sera of 28 of 31 persons with symptomatic giardiasis were immunofluorescent positive, with titres of $1: 50$ to $1: 200$. The IgG, IgM, and IgA serum immunoglobulin levels in these 28 patients, as determined by the Mancini immunodiffusion test, were all either normal or raised. The three giardiasis patients with immunofluorescent negative sera all had decreased immunoglobulin levels. The sera of five patients with other parasitic infections were immunofluorescent negative.

The finding by Ridley and Ridley of circulating antibody against Giardia in $10 / 34$ of their malabsorption patients in whom Giardia could not be demonstrated seems high, and.we agree with them that it cannot be assumed that all 10 patients had cryptic giardiasis.

With the recentireport by Meyer (1976) of a method of axenically cultivating $G$. lamblia, a reliable source of antigen is now available which we plan to use in continuation of the above studies.

\section{References}

Halita, M. and Isaicu, L. (1946). Reactia de fixare a complementului in lambliaza intestinala. Ardeal. med., 6, 154.
Meyer, E. A. (1976). Giardia lamblia: isolation and axenic cultivation Exp. Parasit., 39, 101-105.

Radulescu, S., Meyer, E., Iancu, L., and Simionescu, O. (1974). Some aspects of the immune response in giardiasis. Third International Congress of Parasitology, Munich.

Vinnikov, M. E. (1949). Lambliosis. (In Russian). Sovet. med., 13 (12), 18-20.

SIMONA RADULESCU, LARISSA IANCU, OLGA SIMIONESCU, and ERNEST A. MEYER Cantacuzino Institute and Faculty of Medicine,

Bucharest, Romania, and Department of Microbiology and Immunology,

University of Oregon

Health Sciences Center, Portland, Oregon 97201, USA

\section{Erratum}

Dr R. D. Baynton of Calgary has drawn my attention to an error in my paper reviewing methods for the study of glycosaminoglycan excretion ( $J$. clin. Path., 29, 111, 1976). In the appendix under the heading of Screening Test the formula for the calculation (p. 118) should not include the Figure 10 as denominator and the next sentence should read 'One CPC unit is equivalent to $1 \mathrm{mg}$ of CS' and not 'equivalent to the absorbance given by a solution containing $10 \mathrm{mg}$ CS per litre'.

The error arose because the original description of the method (J. clin. Path., 22, 379, 1969) stated that 'one unit is equivalent to the optical density of a $1 \mathrm{mg}$ per $100 \mathrm{ml}$ solution of chondroitin sulphate'. Conversion of this to the SI unit of volume led to the statement that one unit is equivalent to the absorbance given by a solution containing $10 \mathrm{mg}$ of CS per litre and hence the tenfold error. The unit of volume in the original method is quite irrelevant and hence the conversion was a conceptual error which it took myself and several colleagues a considerable time to recognize. In common with current clinical laboratory practice we all blamed SI units! In spite of the error, the normal range given in table $I$ is correct.

\section{A. PENNOCK \\ Department of Chemical Pathology, Bristol Maternity Hospital}

\section{Book reviews}

The Musculoskeletal System. Edited by Frank C. Wilson. (Pp. xiii + 259; illustrated; $£ 12 \cdot 25$.) Philadelphia: Lippincott. 1975.

This book is concerned with the bones, joints, and muscles of the body together with their associated structures. Its virtue lies in its bringing together in an accessible and readable form the important aspects of their embryology, anatomy, histology, and physiology together with relevant pathological changes and selected clinical features. The wide variety of material is covered in condensed form, assisted by diagrams which are generally simple and helpful. The text is directed to the 'learner' (and all of us are learners in various fields) though recent advances have not been neglected. Pathological processes in bone, joints, and muscle are reasonably well though briefly covered at the level intended, and the last section deals with trauma, especially healing. The book could be helpful to those in training, including young pathologists, and also to those not-so-young who want to revise relatively painlessly the basic information provided. Whether they would be prepared to pay the price asked is another matter.

S. SEVITT

The Immune System. Edited by M. J. Hobart and Ian McConnell. (Pp. xxiii + 357; illustrated, £5-00) Oxford: Blackwell Scientific Publications. 1975.

This multi-author book is based on the course in advanced immunology given at the Royal Postgraduate Medical School, edited so as to be, in effect, a complete text-book of immunology. It is extremely up to date, and all the contributions are excellent, the emphasis being whenever possible on the genetic, biochemical and cellular basis for immunological phenomena. The style is light and easy, but there is no pandering to the beginner, who should first master Roitt's Essential Immunology, while for those interested in the application of modern immunology to disease, it prepares the ground for Gell, Coombs, and Lachman's Clinical Aspects of Immunology. With three such books the student of immunology is now handsomely catered for. The present volume is well produced and laid out with copious 